Published in final edited form as:

Nat Immunol. 2014 October ; 15(10): 929-937. doi:10.1038/ni.2967.

\title{
Constant replenishment from circulating monocytes maintains the macrophage pool in adult intestine
}

\author{
Calum C. Bain ${ }^{\# 1,10}$, Alberto Bravo-Blas ${ }^{\# 1}$, Charlotte L. Scott ${ }^{1,11}$, Elisa Gomez Perdiguero ${ }^{2,3}$, \\ Frederic Geissmann ${ }^{2,3}$, Sandrine Henri ${ }^{4,5,6}$, Bernard Malissen ${ }^{4,5,6}$, Lisa C. Osborne ${ }^{7}$, David \\ Artis $^{7,8}$, and Allan Mcl. Mowat ${ }^{1}$ \\ ${ }^{1}$ Institute of Infection, Immunity and Inflammation, College of Veterinary, Medical and Life \\ Science, University of Glasgow, G12 8TA, Scotland, UK \\ ${ }^{2}$ Centre for Molecular and Cellular Biology of Inflammation (CMCBI), New Hunt's House, King's \\ College London, Great Maze Pond, London SE1 1UL, UK \\ ${ }^{3}$ Peter Gorer Department of Immunobiology, King's College London, London SE1 9RT, UK \\ ${ }^{4}$ Centre d'Immunologie de Marseille-Luminy (CIML), Aix Marseille Universite, Marseille, France \\ 5INSERM U1104, Marseille, France \\ ${ }^{6}$ CNRS UMR7280, Marseille, France \\ ${ }^{7}$ Department of Microbiology and Institute for Immunology, Perelman School of Medicine, \\ University of Pennsylvania, Philadelphia, PA, 19104, USA \\ ${ }^{8}$ Department of Pathobiology, School of Veterinary Medicine, University of Pennsylvania, \\ Philadelphia, PA, 19104, USA \\ \# These authors contributed equally to this work.
}

\section{Abstract}

The paradigm that resident macrophages in steady-state tissues are derived from embryonic precursors has never been investigated in the intestine, which contains the largest pool of macrophages. Using fate mapping models and monocytopenic mice, together with bone marrow chimeric and parabiotic models, we show that embryonic precursors seeded the intestinal mucosa and demonstrated extensive in situ proliferation in the neonatal period. However these cells did not persist in adult intestine. Instead, they were replaced around the time of weaning by the CCR2dependent influx of Ly6 $\mathrm{C}^{\text {hi }}$ monocytes that differentiated locally into mature, anti-inflammatory

\footnotetext{
Users may view, print, copy, and download text and data-mine the content in such documents, for the purposes of academic research, subject always to the full Conditions of use:http://www.nature.com/authors/editorial_policies/license.html\#terms

Correspondence should be addressed to A.M.M. (Allan.Mowat@glasgow.ac.uk).

${ }^{10}$ Current address: MRC Centre for Inflammation Research, Queens Medical Research Institute, University of Edinburgh, Edinburgh, EH16 4TJ, Scotland, UK

${ }^{11}$ Current address: VIB Ghent University, Inflammation Research Centre (IRC), Laboratory of Immunoregulation, Technologiepark 927, B-9052 Ghent (Zwijnaarde), Belgium.

Author Contributions: C.C.B. designed, performed and analyzed experiments and wrote the manuscript. A.B.-B. designed, performed and analyzed experiments. C.L.S. performed experiments. E.P.G., F.G., L.C.O., D.A., S.H. and B.M. provided mice and reagents. A.M.M. designed and supervised the studies and wrote the manuscript.

Competing Interests: The authors have no competing interests to declare.
} 
macrophages. This process was driven largely by the microbiota and had to be continued throughout adult life to maintain a normal intestinal macrophage pool.

\section{Introduction}

Macrophages are found in every tissue of the body, where they act as a first line of defense against pathogenic insult, but also contribute to the maintenance of tissue homeostasis and wound repair ${ }^{1}$. Traditionally macrophages were thought to be part of a linear mononuclear phagocyte system (MPS) and assumed to derive exclusively from blood monocytes ${ }^{2}$. However other more recent work has challenged this concept, generating a paradigm that all macrophage in steady-state tissues are derived from embryonic progenitors in the yolk sac (YS) and/or fetal liver (FL). Thereafter, it has been proposed that these macrophage populations are maintained by self renewal in situ, with little or no contribution from circulating blood monocytes ${ }^{3-8}$. However despite the presence of a large population of functionally specialized macrophages in the intestine ${ }^{9,10}$, these concepts have not been addressed in this tissue.

There is considerable evidence that monocytes can give rise to intestinal macrophages during inflammation in both man and mice ${ }^{11,12}$. Initial studies also showed that 'inflammatory' Ly6 $\mathrm{C}^{\text {hi }}$ monocytes could replenish intestinal macrophages after diphtheria toxin (DT)-mediated intense depletion of myeloid cells in the CD11c-DTR mouse ${ }^{13,14}$. We recently extended these findings by showing that $\mathrm{Ly} 6 \mathrm{C}^{\mathrm{hi}}$ monocytes were present in the colonic mucosa of unmanipulated mice and could enter the intestine after transfer into unmanipulated mice. There they appeared to differentiate locally into mature F4/80 $\mathrm{hi}$ CX3CR $1{ }^{\text {hi }} \mathrm{MHCII}^{+}$macrophages through a series of intermediaries, eventually acquiring the typical properties of gut-resident macrophages, through a process sometimes referred to as the "monocyte waterfall" 15 . The resulting cells showed constitutive production of interleukin 10 (IL-10), phagocytic activity and resistance to stimulation via Toll-like receptors (TLRs) ${ }^{15,16}$. However these studies did not address the possibility that YS and/or FL precursors might seed the intestinal mucosa and persist into adulthood alongside Ly $6 \mathrm{C}^{\text {hi }}$ monocyte-derived macrophages. Furthermore, we could not identify at what stage of development the monocyte dependent replenishment of intestinal macrophages began, and the developmental, environmental and signaling requirements for monocyte recruitment to the intestine remain unexplored.

Here we have used a combination of immunophenotyping, lineage tracing and parabiosis to explore the origin of the intestinal macrophage compartment from birth until adulthood in mice. We show that although YS- and FL-derived macrophages were present in the neonatal intestine, these cells failed to persist into adulthood and instead were diluted out by monocyte-derived macrophages that began to arrive around the time of weaning in a process that is highly dependent on CCR 2 and commensal microbiota. These findings substantially increase our understanding of the regulatory processes that control how intestinal macrophage play critical roles in maintaining epithelial integrity and local homeostasis in this highly dynamic microenvironment ${ }^{10}$. 


\section{Results}

\section{Origins of intestinal macrophages early in life}

To explore the origins of intestinal macrophages, we first developed methods for identifying these cells in the neonatal intestine, by adapting a rigorous gating strategy we had developed in adult mice ${ }^{15,16}$. Live $\left(7-\mathrm{AAD}^{-}\right) \mathrm{CD} 45^{+}$cells could be identified readily in enzymatic digests of colon from newborn mice and as expected, the numbers of live leukocytes rose progressively into adulthood, beginning after the first week of life (Supplementary Fig. 1a). After excluding SiglecF ${ }^{+}$eosinophils, $\mathrm{Ly}_{6 \mathrm{G}^{+}}$neutrophils and $\mathrm{F} 4 / 80^{-} \mathrm{CD} 11 \mathrm{c}^{\text {hi }}$ dendritic cells (DCs), a clear population of $\mathrm{F} 4 / 80^{+} \mathrm{CD} 11 \mathrm{~b}^{+}$cells could be found at E19.5, increasing progressively in numbers up to adulthood (Fig. 1a,b and Supplementary Fig. 1b). In both adult and newborn colon, we confirmed their identity as macrophages on the basis of their abundant expression of the macrophage-specific markers CD64 (Fc $\gamma \mathrm{R} 1)$ and CX3CR1 (Fig. 1c), as well as substantial amounts of surface CD11c and mRNA for the hemoglobinhaptoglobin scavenger receptor CD163 (Supplementary Fig. 1c,d). Interestingly, macrophages in neonatal colon expressed less MerTK than those found in adult colon or F4/80 ${ }^{\text {hi }}$ CD $11 b^{\text {lo }}$ Kupffer cells in the liver (Supplementary Fig. 1e).

We next assessed if these neonatal macrophages were functionally equivalent to their adult counterparts, examining for the high phagocytic activity and constitutive production of IL-10 and tumor necrosis factor (TNF) that characterize steady state macrophages in adult intestine ${ }^{14,16}$. As expected, macrophages from adult colon excelled at taking up fluorescently labeled Escherichia coli into acidified vesicles and similar results were obtained with macrophages from 2-day-old colon (Fig. 1d). Consistent with this evidence of efficient phagocytic activity, both neonatal and adult macrophage were large and highly vacuolar in appearance (Fig.1e). Macrophages sorted from adult intestine also contained high amounts of IL-10 mRNA, together with substantial amounts of TNF mRNA compared with those in CSF-1-treated bone marrow (BM) macrophages used as controls (Fig. 1f). Macrophages from 2-day-old intestine also showed constitutive expression of mRNA for both cytokines, although the abundance of IL-10 mRNA was lower in neonatal than in adult macrophages (Fig. 1f). Together these findings show that cells with the phenotypic and functional properties of resident intestinal macrophages are already present immediately after birth.

Recent studies have proposed that the extent of F4/80 and CD11b expression can be used to identify developmentally distinct macrophage populations in multiple different tissues ${ }^{3}$. Whereas $\mathrm{F} 4 / 80^{\mathrm{hi}} \mathrm{CD} 11 \mathrm{~b}^{\mathrm{lo}}$ are proposed to derive from embryonic precursors, those expressing low amounts of $\mathrm{F} 4 / 80$ but high amounts of $\mathrm{CD} 11 \mathrm{~b}$ appear to originate from conventional hematopoiesis in the adult ${ }^{3}$. Thus we next assessed whether F4/80 and CD11b expression could be used to define discrete macrophage populations in the colon. Clearly definable populations of $\mathrm{F} 4 / 80^{\mathrm{hi}} \mathrm{CD} 11 \mathrm{~b}^{\mathrm{lo}}$ and $\mathrm{F} 4 / 80^{\mathrm{lo}} \mathrm{CD} 11 \mathrm{~b}^{\text {hi }}$ macrophages were seen in the colon of newborn mice, with the $\mathrm{F} 4 / 80^{\text {hi }} \mathrm{CD} 11 \mathrm{~b}^{\mathrm{lo}}$ subset being dominant at this time (Fig. $1 \mathrm{~g})$. Identical populations of $\mathrm{F} 4 / 80^{\mathrm{hi}} \mathrm{CD} 11 \mathrm{~b}^{\mathrm{lo}}$ and $\mathrm{F} 4 / 80^{\mathrm{lo}} \mathrm{CD} 11 \mathrm{~b}^{\text {hi }}$ macrophages were also present in the intestine before birth, confirming their embryonic origin (Fig. 1g). Both subsets expressed substantial amounts of CD64 and CX3CR1, although their expression was 
somewhat higher on the $\mathrm{F} 4 / 80^{\text {hi }} \mathrm{CD} 11 \mathrm{~b}^{\text {lo }}$ subset (Supplementary Fig. 1f). However the distinction between the two phenotypic subsets became progressively less clear in the intestine with age and by adulthood, there were virtually no $\mathrm{F} 4 / 80^{\text {hi }} \mathrm{CD} 11 \mathrm{~b}{ }^{\mathrm{lo}}$ macrophages remaining in the colonic mucosa (Fig. 1a,g). In marked contrast, the monocyte/macrophage compartments found in the liver and spleen showed clear populations of $\mathrm{F} 4 / 80^{\mathrm{hi}} \mathrm{CD} 11 \mathrm{~b}^{\text {lo }}$ and $\mathrm{F} 4 / 80^{\mathrm{lo}} \mathrm{CD} 11 \mathrm{~b}{ }^{\text {hi }}$ cells in adulthood, with the $\mathrm{F} 4 / 80^{\mathrm{hi}} \mathrm{CD} 11 \mathrm{~b}^{\text {lo }}$ remaining the dominant population at this time (Fig. 1h, Supplementary Fig. 1g and data not shown). Thus macrophages bearing the characteristic $\mathrm{F} 4 / 80^{\mathrm{hi}} \mathrm{CD} 11 \mathrm{~b}^{\mathrm{lo}}$ signature of embryonically derived cells remain in tissues such as the liver and spleen, but appear to be lost progressively in the colonic mucosa.

\section{Yolk sac derived macrophages do not persist in adult colon}

As these results suggested that adult intestinal macrophages may be developmentally distinct from those in other tissues, we examined directly whether YS progenitors contribute to the intestinal macrophage pool. To do this we used mice expressing tamoxifen-inducible Cre recombinase under the control of the Csf $1 r$ promoter ${ }^{17}$. These Csf $1 r$-mer-iCre-mer mice were crossed with Rosa26-LSL-YFP reporter mice (referred to as Csfrl-reporter) and Cremediated recombination was induced with a single injection of 4-hydroxy-tamoxifen into pregnant females at E8.5. This protocol leads to irreversible expression of YFP by CSF1R ${ }^{+}$ cells in the YS and their progeny, but not by hematopoietic stem cells (HSCs) or their derivatives ${ }^{3}$. $\mathrm{FP}^{+}$cells were clearly present in the colonic lamina propria of 9-day-old Csflr-reporter mice and all $\mathrm{YFP}^{+}$cells fell within the $\mathrm{F} 4 / 80^{+} \mathrm{CD} 11 \mathrm{~b}^{+}$macrophage gate (Fig. 2a,b). At this age, fewer $\mathrm{YFP}^{+}$cells were found among colonic macrophages than among $\mathrm{F} 4 / 80^{\text {hi }} \mathrm{CD} 11 \mathrm{~b}^{\text {lo }}$ Kupffer cells $(1.7 \pm 0.8 \%$ versus $5.2 \pm 0.1 \%$, respectively), perhaps reflecting tissue-specific differences in the efficiency of Cre-mediated labeling ${ }^{3}$, or that monocytederived cells were already appearing in the colon by this time (Fig. 2b). This difference was even more marked in adult $C s f 1 r$-reporter mice, where $\mathrm{YFP}^{+}$cells remained readily detectable in the liver, albeit at reduced numbers, whereas the colon contained very few $\mathrm{YFP}^{+}$of the same mice (Fig. 2b). The reduction in $\mathrm{YFP}^{+}$macrophages in adult intestine was not simply due to dilution by other cells, as their absolute number was also significantly lower in adult colon than in 9-day-old intestine (Fig. 2c). Consistent with exclusive labeling of YS-derived cells, $\mathrm{YFP}^{+}$cells could not be detected among Ly6Chi blood monocytes at any time (Fig. 2b). Thus although YS-derived macrophages are present in the intestine early in life, they do not persist in the adult gut to any significant extent.

\section{Colon macrophages derive from conventional hematopoiesis}

Given the apparent paucity of YS-derived macrophages in the adult intestine, we next used Flt3-Cre Rosa26-LSL-YFP reporter mice (referred to as Flt3-reporter mice) to assess the contribution of conventional hematopoiesis to the intestinal macrophage pool. As the cytokine receptor Flt3 is expressed by all pluripotent hematopoietic progenitors in the BM, the progeny of these cells become permanently $\mathrm{YFP}^{+}$in Flt3-reporter mice ${ }^{3} .50-60 \%$ of total

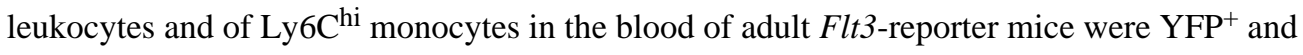
similar proportions of $\mathrm{YFP}^{+}$cells were also seen among macrophages in the adult colon (Fig. 2d). This evidence that intestinal macrophages are derived from conventional hematopoiesis was supported further by the fact that virtually all colonic macrophages were 
eliminated by whole body irradiation and were replaced by BM-derived progenitors in BM chimeras (Fig. 2e). In stark contrast, very few F4/80 hi CD11b ${ }^{\text {lo }}$ Kupffer cells (4.6 $\pm 2.1 \%$ ) were labeled in Flt3-reporter mice (Fig. 2d), and large proportions of Kupffer cells and splenic macrophages remained of host origin in radiation chimeras, consistent with previous reports that these cells are radio-resistant ${ }^{18}$ (Fig. 2e). Taken together, these results suggest that although YS-derived cells seed the intestinal lamina propria early in development, they are replaced by the progeny of conventional hematopoiesis in adulthood.

\section{Ly6C $^{\text {hi }}$ monocytes drive colonic macrophage accumulation}

We reasoned that this switch from embryonic to hematopoietic origin might occur at the time when we observed the most intense increase in the number of macrophages, 2-3 weeks after birth. To test this hypothesis, we carried out a comprehensive analysis of the macrophage compartment from birth to adulthood. Confirming our previous findings ${ }^{15,16}$, we could identify 3 subsets of $\mathrm{F} 4 / 80^{+} \mathrm{CD} 11 \mathrm{~b}^{+}$cells based on their expression of $\mathrm{Ly} 6 \mathrm{C}$ and MHCII in the colon of adult wild-type mice (Fig. 3a). Colonic $\mathrm{Ly}^{6} \mathrm{C}^{\text {hi }} \mathrm{MHCII}^{-}$cells were phenotypically similar to classical blood monocytes ${ }^{19}$, expressing intermediate amounts of CX3CR1 and high amounts of CCR2 (Fig. 3b), whereas the $\mathrm{LyCC}^{+} \mathrm{MHCII}^{+}$cells showed loss of CCR2 expression and upregulation of CX3CR1; this finding is consistent with these cells being an intermediary stage between Ly6 $\mathrm{C}^{\mathrm{hi}}$ monocytes and resident macrophages ${ }^{15,16}$ (Fig. 3b). The majority of $\mathrm{F} 4 / 80^{+} \mathrm{CD} 11 \mathrm{~b}^{+}$cells was $\mathrm{Ly} 6 \mathrm{C}^{-}$and had the CX3CR1 ${ }^{\text {hi }} \mathrm{CCR} 2^{-}$ phenotype of mature macrophages (Fig. 3b). Whereas the numbers of mature $\mathrm{Ly}^{-} \mathrm{C}^{-}$ macrophages increased progressively with age, there were very few $\mathrm{Ly}^{6} \mathrm{C}^{\text {hi }} \mathrm{MHCII}^{-}$cells in the intestine of wild-type mice at the time of birth and their numbers remained very low until after 14 days of life (Fig. 3c). Notably, the $\mathrm{Ly}^{6} \mathrm{C}^{+} \mathrm{MHCII}^{+}$cells were essentially absent from the colonic mucosa until around three weeks of life, suggesting that differentiation of classical monocytes through the 'monocyte waterfall' does not occur until 2-3 weeks of life. Furthermore, the appearance of $\mathrm{Ly}_{6} \mathrm{C}^{+} \mathrm{MHCII}^{+}$intermediaries was paralleled by a progressive acquisition of MHCII expression by mature $\mathrm{Ly} 6 \mathrm{C}^{-}$macrophages (Fig. 3d).

To assess the contribution of classical blood monocytes at this time, we examined $C \mathrm{cr} 2^{-/-}$ mice in whom Ly6 $\mathrm{C}^{\text {hi }}$ monocyte egress from the BM is defective ${ }^{20}$. Although all Ly6C-and MHCII-defined populations of macrophages were present in normal numbers in newborn $\mathrm{Ccr} 2^{-/-}$mice, progressively severe deficiencies in $\mathrm{Ly}_{6} \mathrm{C}^{\text {hi }} \mathrm{MHCII}^{-}$and $\mathrm{Ly}_{6 \mathrm{C}}^{+} \mathrm{MHCII}{ }^{+}$cells relative to wild-type mice of the same ages appeared after 7 days of age (Fig. 3e and Supplementary Fig. 2a,b). By adulthood, these cells were essentially absent from $\mathrm{Ccr} 2^{-/-}$ colon (Fig. 3e-g). In contrast, the numbers of mature Ly6 $6 \mathrm{C}^{-}$macrophages in $\mathrm{Ccr} 2^{-/-}$colon remained equivalent to those in wild-type mice until 7 weeks of age, when there was a 50\% deficit in their numbers (Fig. 3e-g). Notably, this defect developed further with age, with 9-12-month-old $\mathrm{Ccr}^{-/-}$mice showing a much more severe defect in the numbers of mature Ly6C $\mathrm{C}^{-}$macrophages compared with their younger counterparts (Fig. 3e and Supplementary Fig. 2c). The absence of CCR2 did not affect other tissue-resident macrophage populations, with the numbers of $\mathrm{F} 4 / 80^{\mathrm{hi}} \mathrm{CD} 11 \mathrm{~b}^{\text {lo }}$ Kupffer cells in the liver being normal in adult $\mathrm{Ccr} 2^{-/-}$ mice, consistent with them being embryonically derived (Fig. 3h). Conversely, $\mathrm{Ccr}^{-/-}$ livers had significantly reduced numbers of $\mathrm{F} 4 / 80^{\mathrm{lo}}$ cells, which are presumptively derived from classical monocytes. 
Interestingly, despite their normal numbers in 3-week-old $\mathrm{Ccr}^{-/-}$colon, a proportion of the mature $\mathrm{Ly}_{6 \mathrm{C}}{ }^{-}$macrophages seen in these mice remained $\mathrm{MHCII}^{-}$, when all $\mathrm{Ly}_{6} \mathrm{C}^{-}$cells had become $\mathrm{MHCII}^{+}$in wild-type colon (Fig. 3d and Supplementary Fig. 2a,c). A small population of $\mathrm{MHCII}^{\mathrm{lo}} \mathrm{Ly} 6 \mathrm{C}^{-}$macrophages also remained present in adult $\mathrm{Ccr} 2^{-/-}$colon (Fig. 3f,g). Together these data suggest that the adult colonic macrophage pool first becomes established around the time of weaning at 2-3 weeks of age and that this is associated with CCR2-dependent accumulation of Ly6 $\mathrm{C}^{\text {hi }}$ monocytes and their subsequent differentiation into MHCII-expressing macrophages.

\section{Macrophages proliferate in neonatal, but not adult colon}

Given that the abundance of mature $\mathrm{Ly} 6 \mathrm{C}^{-}$macrophages remained normal in $\mathrm{Ccr} 2^{-/-}$mice until adulthood, despite the severe reduction in classical blood monocytes, we next tested the hypothesis that there may be in situ proliferation of the embryonically derived macrophages which were clearly present at birth. To examine this we assessed the expression of the Ki67 antigen, which is expressed exclusively by cells in active cell cycle. At 2 days of age, around $30 \%$ of mature $\mathrm{Ly}_{6 \mathrm{C}^{-}}$macrophages $\left(\mathrm{MHCII}^{+}\right.$and $\mathrm{MHCII}^{-}$) from the colon showed high Ki67 expression and similar results were seen with macrophages from 2 week old mice, before the numbers of $\mathrm{Ki} 67^{+}$macrophages fell significantly at 3 weeks (Fig. 4a,b). By 5 weeks of age, the frequency of Ki6 $7^{+}$macrophages had decreased further, roughly around the limit of detection, and this remained the case for macrophages from older adults (Fig. $4 \mathrm{a}, \mathrm{b})$. There were no differences between the $\mathrm{MHCII}^{+}$and $\mathrm{MHCII}^{-}$subsets of $\mathrm{Ly}^{-} \mathrm{C}^{-}$ mature macrophage in terms of Ki67 expression, indicating that this phenotypic distinction does not correlate with an ability to self-renew (Supplementary Fig. 3). Similarly, those $\mathrm{F} 4 / 80^{\text {hi }} \mathrm{CD} 11 \mathrm{~b}^{\text {lo }}$ macrophages that could be identified discretely in adult colon did not differ in Ki67 expression, as would be expected if proliferative capacity was restricted to any remaining embryonically derived cells (Supplementary Fig. 3). The changing pattern of Ki67 expression by colonic macrophages was not a property of all myeloid cells in the mucosa during development, as intestinal eosinophils failed to express Ki67 at any time point (Supplementary Fig. 3), while mucosal DC displayed high expression of Ki67 at all times from birth until adulthood, consistent with the known ability of mature tissue DCs to divide in situ ${ }^{21}$ (Fig. 4c). It is well known that certain macrophage populations display enhanced proliferative capacity following acute inflammation in an attempt to replenish their numbers ${ }^{4,22,23}$. However we found no evidence for increased cell division by any of the populations of monocytes/macrophages defined on expression of Ly6C/MHCII during acute colitis induced by oral administration of dextran sodium sulfate (DSS), or in the period of tissue repair after removal of DSS (Fig. 4d). Thus resident intestinal macrophages proliferate in situ in the first few weeks of life, but this diminishes in parallel with the arrival of BMderived monocytes around 3 weeks of age. Although the adult macrophages retain some capacity to divide locally, this does not appear to account for the maintenance of this population in the steady state, or during their response to inflammation.

\section{Monocytes maintain macrophages in steady state colon}

Thus far, our results indicate that the macrophage pool in adult intestine is derived from classical hematopoiesis, rather from self-renewing YS-derived precursors and that this process needs to be continued throughout adult life to maintain normal numbers of 
macrophages. To study this in more detail, we used a parabiotic approach, in which blood monocytes were able to exchange between adult hosts. Congenic wild-type CD45.1 $1^{+}$and CD45.2 $2^{+}$mice were joined surgically and the presence of non-host cells was assessed in each parabiont 10 weeks later. Confirming that there had been efficient exchange between the circulations at this time, B and T lymphocytes in the bloodstream showed an approximately 50:50 mix of host:donor origin, regardless of which parabiont was examined (Fig. 5a). As reported previously ${ }^{7,24}$, the degree of chimerism of myeloid cells was considerably lower than that of lymphocytes, with Ly6Chi blood monocytes showing $~ 12 \%$ chimerism in either partner (Fig. 5a). Similar frequencies of chimerism were found among all the populations of $\mathrm{Ly}_{6} \mathrm{Ch}^{\mathrm{MHCII}}{ }^{-}, \mathrm{Ly} 6 \mathrm{C}^{+} \mathrm{MHCII}^{+}$and $\mathrm{Ly}^{-} \mathrm{C}^{-} \mathrm{MHCII}^{+}$macrophages in the colon, with $\sim 10 \%$ deriving from the opposite parabiont in each case (Fig. 5a).

We next examined the role of CCR2 in the replenishment of the adult macrophage pool, first by analyzing mixed BM chimeric mice that had been reconstituted with a 50:50 mice of wild-type and $\mathrm{Ccr}^{-/-}$BM. As expected, there was a marked bias towards reconstitution of Ly6 $\mathrm{C}^{\text {hi }}$ monocytes in blood from wild-type BM in these mice (Fig. 5b). In parallel, macrophages in the colon were derived almost exclusively from wild-type BM in these animals. Indeed, even fewer intestinal macrophages were derived from $\mathrm{Ccr} 2^{-/-} \mathrm{BM}$ compared with circulating Ly $6 \mathrm{C}^{\text {hi }}$ monocytes in the same animals $(0.5 \%$ versus $\sim 4 \%$, Fig. $5 b$ ), suggesting that CCR2 is required for entry to the colonic mucosa, in addition to its role in BM egress. In contrast, eosinophils of $\mathrm{Ccr}^{-/-}$origin accumulated normally in the intestine of chimeric mice, indicating successful engraftment of both types of BM (Fig. 5b). These results did not reflect potential disruption of intestinal homeostasis by irradiation, as similar findings were obtained in wild-type: $C \mathrm{cr} 2^{-/-}$parabiotic mice (wild-type). Under these conditions, wild-type-derived macrophages were readily detected in the colon of the $\mathrm{Ccr} 2^{-/-}$parabionts, whereas $\mathrm{Ccr} 2^{-/-}$derived macrophages could not be found in the colon of their wild-type partner (Fig. 5c). The same pattern of chimerism was not seen when $\mathrm{F} 4 / 80^{\text {hi }} \mathrm{CD} 11 \mathrm{~b}^{\text {lo }}$ Kupffer cells in the liver of these parabionts were examined, where no exchange between either partner could be seen, consistent with their independence from circulating monocytes (Fig. 5c). Together these results confirm that the adult intestinal macrophage pool requires constant replenishment by CCR2-dependent recruitment of Ly6 ${ }^{\text {hi }}$ monocytes.

\section{The microbiota regulates the colonic macrophage pool}

As this need for continuous replenishment by monocytes marks the intestine out from other tissues, we reasoned that this may be driven by local signals, such as the commensal microbiota. To test this hypothesis, we first administered broad-spectrum antibiotics (Abx) to conventionally reared wild-type mice for two weeks. This protocol has been described to alter the composition and burden of commensal bacteria in the intestine ${ }^{25}$. In our hands, it resulted in small, but significant reductions in the numbers of the $\mathrm{Ly}^{6} \mathrm{C}^{\mathrm{hi}} \mathrm{MHCII}{ }^{-}$and $\mathrm{Ly}_{6 \mathrm{C}^{+}} \mathrm{MHCII}^{+}$monocyte-like subsets in the colon, but not in the number of $\mathrm{Ly}^{-} \mathrm{C}^{-} \mathrm{MHCII}^{+}$ mature macrophages (Supplementary Fig. 4). We next depleted the microbiota under conditions in which CCR2-dependent recruitment of monocytes could be assessed by parabiosis. Wild-type: $C \mathrm{Cr} 2^{-/-}$parabionts received antibiotics for either the first 4 weeks after surgery, or for the entire period before the degree of non-host chimerism was assessed 
in the $\mathrm{Crr} 2^{-/-}$parabionts at 8 weeks. We found a higher degree of chimerism in parabionts that had only received antibiotics for the first 4 weeks after surgery compared with those receiving continuous antibiotics ( $\sim 40 \%$ versus $\sim 60 \%$; Fig. $6 \mathrm{a}$ ).

As the accumulation of colonic macrophages between 2-3 weeks of age coincides with acquisition of commensal bacteria, we addressed the hypothesis that commensal bacteriaderived signals may be essential for the burst of monocyte-derived colonic macrophages. Analysis of the colonic macrophage compartment in germ-free mice revealed strikingly fewer of all the monocyte-macrophage subsets in the colon of adult germ-free mice compared with conventionally housed controls (Fig. 6b). Importantly, at 3 weeks of age, there were very few $\mathrm{Ly}_{6 \mathrm{Ch}} \mathrm{MHCII}^{-}$and $\mathrm{Ly}_{6 \mathrm{C}} \mathrm{MHCII}^{+}$cells in the germ-free colon compared with conventionally housed mice (Fig. 6c). This was paralleled by a decrease in the numbers of mature Ly6C ${ }^{-}$macrophages (Fig. 6c) and significantly fewer of these expressed MHCII than among Ly6C ${ }^{-}$macrophages in wild-type colon ( $40 \%$ vs $\sim 80 \%$, Fig. $6 \mathrm{~d})$. Together these data support the idea that the defect in macrophage numbers seen in germ-free conditions might reflect impaired recruitment of the monocytes that normally begin to replenish the intestinal macrophage population around weaning. Consistent with this we found no difference in the abundance of $\mathrm{Ly} \mathrm{C}^{-}$macrophages in the colonic mucosa of 7-day-old germ-free mice compared with conventionally housed mice (data not shown). Together these experiments indicate that homeostasis of resident intestinal macrophage requires microbiota and CCR2-dependent recruitment of classical monocytes.

\section{Discussion}

The concept of the MPS in which blood monocytes replenish tissue macrophages has been called into question recently by a new paradigm proposing that tissue macrophages arise from embryonic precursors and are independent of blood monocytes ${ }^{3,4,6}$. Here we show that the intestinal mucosa is an exception to this idea. Although seeded early in life by embryonic precursors, the colonic macrophage compartment becomes entirely dependent on constant replenishment by classical Ly6 $\mathrm{C}^{\text {hi }}$ blood monocytes.

Macrophages could be identified readily in newborn and late fetal intestine, where they comprised a mixture of the $\mathrm{F} 4 / 80^{\mathrm{hi}} \mathrm{CD} 11 \mathrm{~b}^{\mathrm{lo}}$ and $\mathrm{F} 4 / 80^{\mathrm{lo}} \mathrm{CD} 11 \mathrm{~b}^{+}$cells proposed to be derived from the YS and fetal liver respectively ${ }^{3,5}$. Csf1r and Flt3 driven fate mapping confirmed the presence of YS-derived macrophages in the neonatal intestine, but they were virtually absent from the adult mucosa, where they were replaced by the progeny of conventional hematopoiesis. This contrasts with the liver, lung, spleen, kidney, epidermis and brain, where macrophages retain their embryonic signature into adulthood ${ }^{3,4,26}$. Although there was also an apparent age-related decrease in the frequency of labeled liver Kupffer cells in the Csflr-reporter mouse, the vast majority of these remained independent of conventional hematopoiesis. Notably, there were already fewer labeled colonic macrophages in of day 9 Csfl $r$-reporter mice compared with amongst Kupffer cells, perhaps indicating that conventional hematopoietic precursors had already entered the intestine by this time. 
Our parabiosis studies supported a direct precursor-product relationship between Ly6 $\mathrm{C}^{\mathrm{hi}}$ monocytes and colonic macrophages. Although Ly6 $\mathrm{C}^{\text {hi }}$ monocytes have been shown to replenish intestinal CX3CR $1^{+} \mathrm{F} 4 / 80^{+}$cells by other investigators ${ }^{13,27}$, this was following intense depletion of resident cells. Here we have extended our previous findings that adoptively transferred Ly6 $\mathrm{C}^{\text {hi }}$ monocytes enter the steady state colonic mucosa ${ }^{16}$, by showing that the monocyte replenishment process becomes essential for maintaining the colonic macrophage pool. This was also evidenced by the severe deficit in colonic macrophages found in older $\mathrm{Ccr} 2^{-/-}$mice. In contrast, most other tissue macrophages show poor exchange during parabiosis ${ }^{4,7,28,29}$ and are unaffected by CCR2-deficiency $26,30,31$. Interestingly however, skin dermal macrophages have been shown to be partly dependent on CCR2 and to exchange during parabiosis, suggesting that some of these cells may also require replenishment by Ly6C $\mathrm{C}^{\text {hi }}$ monocytes ${ }^{28}$.

We cannot exclude the possibility that small numbers of embryonically derived macrophages may remain present in the intestine throughout adult life. Indeed, as the fate mapping systems used to identify the progeny of YS derived precursors show relatively low efficiencies of recombination, they probably underestimate the true size of these populations ${ }^{32}$. The presence of colonic macrophages in adult $\mathrm{Ccr}^{-/-}$mice could also argue for the persistence of macrophages from primitive sources, although it must be noted that $C \mathrm{cr} 2^{-/-}$mice do have circulating Ly $6 \mathrm{C}^{\mathrm{hi}}$ monocytes, albeit $\sim 90 \%$ fewer than wild-type mice. Nevertheless, the numbers of YS-derived macrophages in the intestine were $\leq 1000$ labeled cells/intestine, suggesting that such cells may not make a substantial contribution to the adult compartment.

During the neonatal period, colonic macrophages showed high levels proliferation, similar to that seen with other macrophages early in life ${ }^{5,22,30}$. However, following the onset of monocyte accumulation, the proliferative capacity of colonic macrophage diminished, supporting previous studies showing a low turnover rate of mature intestinal macrophages in $s_{i t u} 16,33$. Adult colonic macrophages also failed to show a capacity to self renew in response to acute inflammation, or during its repair phase, situations where embryonically-derived macrophages proliferate in other organs ${ }^{4,22,23,30,34}$. Thus the mechanism maintaining the colonic macrophage compartment reflects a unique switch from local proliferation to replenishment by Ly6C ${ }^{\text {hi }}$ blood monocytes.

Because the most dramatic changes in macrophage number and monocyte recruitment occurred during the third week of life, we considered that this could reflect establishment of the microbiota. Previous studies have reached discrepant conclusions on the abundance of colonic macrophages in germ-free mice ${ }^{14,35,36}$ and we found that although these mice had a normal intestinal macrophage compartment at birth, they had markedly reduced monocyte recruitment at 3 weeks of age. As a result, adult germ-free mice had significantly fewer of all the subsets within the so-called monocyte "waterfall" 16,37 . This effect was partially recapitulated by administering broad spectrum antibiotics to conventionally housed adult mice, although this had no effect on mature macrophages. This might reflect the short duration of antibiotic regime in comparison with the half life of mature cells, which we estimate at $\sim 4-6$ weeks on the basis our studies of parabiotic and $C \mathrm{cr} 2^{-/-}$mice. Antibiotic treatment also reduced the recruitment of non-host monocytes into the intestine of parabiotic 
partners and taken together, these results demonstrate definitively that the microbiota influences the kinetics of macrophage replenishment in the colonic mucosa. Notably, this contrasts with the recruitment of Ly6 $\mathrm{Chi}^{\text {hi }}$ monocytes to other barrier surfaces such as the skin dermis $^{28,29}$.

Nevertheless it is intriguing to note that all stages of the monocyte-macrophage waterfall could be detected in adult germ-free colon, as well as in conventional small intestine where the microbial burden is much lower. That the microbiota is not the only factor involved in the homeostasis of intestinal macrophages is supported by our findings that although macrophages in the neonatal and adult intestine have distinct origins, they shared many of the features that make of intestinal macrophages unique. Both expressed high levels of CX3CR1 and scavenger receptors, were avidly phagocytic and produced IL-10 and TNF constitutively, but were hyporesponsive to TLR stimulation (data not shown). Thus intestinal macrophages may have similar roles in the presence or absence of the microbiota, irrespective of the stage of host development (Supplementary Fig.5) Likely functions of this kind could include removal of dying epithelial cells and tissue remodeling, highly appropriate to such a rapidly dividing organ. Indeed, apoptotic debris from epithelial cells has been observed in LP macrophage ${ }^{38,39}$.

Our results indicate that the ontogeny of resident tissue macrophages is more complex than can be explained only by the paradigms of the MPS or embryonic origin. Rather, the relative contributions of these sources depends on the tissue, with different anatomical and microbiological factors demanding distinct forms of adaptation. The intestine is at one end of the spectrum, as its continual exposure to environmental stimuli warrants constant replenishment by highly plastic blood monocytes (Supplementary Fig.5). Conversely, the physiological demands of tissue remodeling may dominate over responsiveness to external agents in the brain, epidermis and alveolar space, and are best served by a stable population of embryonically derived macrophages throughout life. Tissues like the liver, dermis, heart and spleen appear to exhibit a mixed pattern of origin, allowing stability and flexibility to be combined. Importantly, all tissues can readily recruit classical monocytes when infection or tissue damage demand a rapid and flexible reaction, mirroring the position that occurs on a daily basis in the intestine.

\section{Methods}

Mice

Wild-type C57BL/6 (B6) (Harlan Olac), $C x 3 c r 1^{+/ g f p 40}$ and $C c r 2^{-/-41}$ ) mice were maintained under specific pathogen-free conditions at the Central Research Facility at the University of Glasgow, UK. $C c r 2^{+/ r f p}$ mice ${ }^{19}$ were maintained at the Division of Neuroimmunology, Roslin Institute, University of Edinburgh. Csflr-mer-Cre-mer ${ }^{17}$, Flt3-Cre ${ }^{42}$ and Rosa26LSL-YFP mice have been described previously ${ }^{3}$ and were maintained at the Centre for Molecular and Cellular Biology of Inflammation, King's College London, UK. GF mice were maintained in the University of Pennsylvania Gnotobiotic Mouse Facility. GF mice were confirmed to be free of all culturable bacteria prior to and at the culmination of all experiments. Conventionally housed counterparts were bred and maintained at the Perelman School of Medicine, University of Pennsylvania, USA. All mice had been backcrossed for at 
least nine generations on to the B6 background and were used between embryonic day 19.5 and 12 weeks, unless stated otherwise. For determining the stage of development, vaginal plug formation was taken as 0.5 day post-coitum (d.p.c.). All experiments were carried out according to UK Home Office regulations or in agreement with University of Pennsylvania Institutional Animal Care and Use Committee-approved protocols.

\section{Generation of parabiotic mice}

CD45.1 $1^{+}$WT mice were sutured to either CD45.2 $2^{+}$WT or $C c r 2^{-1-}$ mice and left for 8-10 weeks before blood and organs were assessed for the level of non-host chimerism. All mice were 9 weeks old at the time of surgery and kept under ibuprofen treatment started few days before the surgery. Mice received either Bactrim for the entire period after surgery, or an antibiotic cocktail containing ampicillin $(1 \mathrm{~g} / \mathrm{l})$, neomycin $(1 \mathrm{~g} / \mathrm{l})$, metrodinazole $(1 \mathrm{~g} / \mathrm{l})$ and vancomycin $(0.5 \mathrm{~g} / \mathrm{l})$ for only the first 4 weeks following surgery, before returning to normal drinking water. Antibiotics were replaced weekly.

\section{Generation of bone marrow chimeric mice}

7-8-week-old CD $45.1^{+} \mathrm{CD} 45.2^{+}$WT mice were lethally irradiated with 2 doses of $5 \mathrm{~Gy}, 2 \mathrm{~h}$ apart and then reconstituted immediately with $5 \times 10^{6} \mathrm{BM}$ cells from CD45.1 $1^{+} \mathrm{WT}$ and $\mathrm{CD} 45.2^{+} \mathrm{Ccr} 2^{-/-}$mice at a 50:50 ratio by intravenous infusion. Mice were left for 8 weeks before blood and organs were assessed for chimerism.

\section{Pulse labeling of YS derived macrophages}

To label YS derived macrophages, tamoxifen-inducible Csfl $r$-mer-iCre-mer transgenic mice were crossed with homozygous Rosa26-LSL-YFP reporter mice and pregnant females were given a single intraperitoneal injection of $75 \mathrm{~g} / \mathrm{g}$ bodyweight 4-hydroxytamoxifen (4'OHT, Sigma) and $37.5 \mu \mathrm{g} / \mathrm{g}$ progesterone at E8.5 to induce Cre-mediated recombination as described previously ${ }^{3}$.

\section{Isolation of tissue leukocytes}

Lamina propria cells were obtained from fetal, neonatal and adult mouse colon by enzymatic digestion as described previously ${ }^{12,43}$. For isolation of colonic LP cells from E18.5 fetal mice, pregnant females were sacrificed by cervical dislocation, fetuses were dissected out of the uterus and washed in ice-cold phosphate-buffered saline (PBS). For the isolation of liver leukocytes, livers were removed from perfused mice, chopped finely and incubated in prewarmed $1.25 \mathrm{mg} / \mathrm{ml}$ collagenase D (Roche), $0.85 \mathrm{mg} / \mathrm{ml}$ collagenase V (Sigma-Aldrich), 1 mg dispase (Gibco, Invitrogen), and $30 \mathrm{U} / \mathrm{ml}$ DNase (Roche Diagnostics $\mathrm{GmbH}$ ) in RPMI-1640 for 20-30 minutes in a shaking incubator at $37^{\circ} \mathrm{C}$.

\section{Flow cytometric analysis and sorting of cells}

$0.5-5 \times 10^{6}$ cells were stained at $4^{\circ} \mathrm{C}$ in the dark as described previously ${ }^{43}$, using the antibodies listed in Supplementary Table 1 and analyzed using an LSR II or FACSAria I cytometer (BD Biosciences) and FlowJo software (Tree Star). Colonic macrophages were sorted as live gated $\mathrm{CD}_{4} 5^{+}$SiglecF ${ }^{-} \mathrm{Ly}_{6 \mathrm{G}^{-}} \mathrm{CD} 11 \mathrm{c}^{\text {int }} \mathrm{F} 4 / 80^{\text {hi }}$. For morphological assessment, sorted cells were spun onto Polysine ${ }^{\mathrm{TM}}$ glass microscope slides (VWR 
International), fixed in acetone and stained using the Rapid-Romanowsky staining kit (Raymond A. Lamb Ltd).

\section{Assessment of proliferation}

For the detection of Ki67 expression, 3-4 × $10^{6}$ cells were first incubated with fixable viability dye eFluor780 (eBioscience), before being incubated with anti-CD16/CD32 to block Fc receptors and then stained with the appropriate surface markers, all at $4^{\circ} \mathrm{C}$. Cells were then fixed and permeabilized with Foxp3 staining buffer set overnight at $4^{\circ} \mathrm{C}$ (eBioscience), before staining for $\mathrm{Ki} 67$ (BD Bioscience) for $30 \mathrm{~min}$ at $20^{\circ} \mathrm{C}$. In some experiments, mice were injected i.p. with $1 \mathrm{mg}$ BrdU (BD Biosciences) and the incorporation of BrdU by isolated cells was assessed after $3 \mathrm{~h}$ using the BD BrdU Flow Kit (BD Biosciences).

\section{Assessment of phagocytosis}

1-3 $\times 10^{6}$ cells were cultured with pHrodo Escherichia coli bioparticles (Life Technologies) according to the manufacturer's guidelines and analyzed by flow cytometry.

\section{Induction of colitis}

Mice received 2\% DSS (reagent grade; MW 36-50 kDa; MP Biomedicals), ad libitum in sterile drinking water for 3 days. To assess the recovery phase, mice were then returned to normal drinking water for 3 days.

\section{Quantitation of gene expression by real-time reverse transcription PCR}

Total RNA was extracted from FACS-purified F4/80 hi cells from the colon of individual adult mice or from pooled neonatal colons using the RNeasy Micro kit (Qiagen). RNA were reverse transcribed to cDNA using the Superscript II First strand synthesis system (Invitrogen) and gene expression was assayed by quantitative reverse transcription PCR using Brilliant III Ultra Fast SYBR qPCR master mix (Agilent Technologies) on the 7500HT Fast system (Applied Biosystems) and with the primers (Integrated DNA Technologies) detailed in Supplementary Table 2. Complementary DNA samples were assayed in triplicate and gene expression levels were normalized to Cyclophilin A. The mean relative gene expression was calculated using the $2^{-\mathrm{d} \Delta \mathrm{C}(\mathrm{t})}$ method.

\section{Statistical analysis}

Results are presented as mean \pm 1 s.d. and groups were compared using a Student's $t$-test, Mann-Whitney test or for multiple groups, a one-way ANOVA followed by a Bonferroni post test using Prism Software (GraphPad Software).

\section{Supplementary Material}

Refer to Web version on PubMed Central for supplementary material. 


\section{Acknowledgements}

We would like to thank D. Vaughan from the Flow Cytometry Core Facility at the University of Glasgow and B. McColl from the Roslin Institute, Edinburgh for the CCR2-reporter mice. We would also like to thank V. Cerovic for critical reading of the manuscript.

C.C.B., A.M.M. and C.L.S. were funded by The Wellcome Trust and MRC UK; A.B.-B. was funded by Conacyt (Mexico) and Tenovus Scotland; S.H. and B.M. were supported by the EE-ASI European Collaborative Research Project and the Agence National de Recherche (France).

\section{References}

1. Davies LC, Jenkins SJ, Allen JE, Taylor PR. Tissue-resident macrophages. Nat. Immunol. 2013; 14:986-995.

2. van Furth R, et al. The mononuclear phagocyte system: a new classification of macrophages, monocytes, and their precursor cells. Bull World Health Organ. 1972; 46:845-852. [PubMed: 4538544]

3. Schulz C, et al. A lineage of myeloid cells independent of Myb and hematopoietic stem cells. Science (New York, N.Y. 2012; 336:86-90.

4. Hashimoto D, et al. Tissue-resident macrophages self-maintain locally throughout adult life with minimal contribution from circulating monocytes. Immunity. 2013; 38:792-804. [PubMed: 23601688]

5. Hoeffel G, et al. Adult Langerhans cells derive predominantly from embryonic fetal liver monocytes with a minor contribution of yolk sac-derived macrophages. J. Exp. Med. 2012; 209:1167-1181. [PubMed: 22565823]

6 . Yona $\mathrm{S}$, et al. Fate mapping reveals origins and dynamics of monocytes and tissue macrophages under homeostasis. Immunity. 2013; 38:79-91. [PubMed: 23273845]

7. Guilliams M, et al. Alveolar macrophages develop from fetal monocytes that differentiate into longlived cells in the first week of life via GM-CSF. J. Exp. Med. 2013; 210:1977-1992. [PubMed: 24043763]

8. Ajami B, Bennett JL, Krieger C, Tetzlaff W, Rossi FM. Local self-renewal can sustain CNS microglia maintenance and function throughout adult life. Nat. Neurosci. 2007; 10:1538-1543. [PubMed: 18026097]

9. Lee SH, Starkey PM, Gordon S. Quantitative analysis of total macrophage content in adult mouse tissues. Immunochemical studies with monoclonal antibody F4/80. J. Exp. Med. 1985; 161:475489. [PubMed: 3973536]

10. Bain CC, Mowat AM. The monocyte-macrophage axis in the intestine. Cell. Immunol. 2014 doi: 10.1016/j.cellimm.2014.03.012.

11. Grimm MC, et al. Direct evidence of monocyte recruitment to inflammatory bowel disease mucosa. J Gastroenterol Hepatol. 1995; 10:387-395. [PubMed: 8527703]

12. Platt AM, Bain CC, Bordon Y, Sester DP, Mowat AM. An independent subset of TLR expressing CCR2-dependent macrophages promotes colonic inflammation. J. Immunol. 2010; 184:68436854. [PubMed: 20483766]

13. Varol C, et al. Intestinal lamina propria dendritic cell subsets have different origin and functions. Immunity. 2009; 31:502-512. [PubMed: 19733097]

14. Rivollier A, He J, Kole A, Valatas V, Kelsall BL. Inflammation switches the differentiation program of Ly6Chi monocytes from antiinflammatory macrophages to inflammatory dendritic cells in the colon. J. Exp. Med. 2012; 209:139-155. [PubMed: 22231304]

15. Tamoutounour S, et al. CD64 distinguishes macrophages from dendritic cells in the gut and reveals the Th1-inducing role of mesenteric lymph node macrophages during colitis. Eur. J. Immunol. 2012; 42:3150-3166. [PubMed: 22936024]

16. Bain CC, et al. Resident and pro-inflammatory macrophages in the colon represent alternative context-dependent fates of the same Ly6Chi monocyte precursors. Mucosal Immunol. 2013; 6:498-510. [PubMed: 22990622] 
17. Qian B-Z, et al. CCL2 recruits inflammatory monocytes to facilitate breast-tumour metastasis. Nature. 2011; 475:222-225. [PubMed: 21654748]

18. Kennedy DW, Abkowitz JL. Kinetics of central nervous system microglial and macrophage engraftment: analysis using a transgenic bone marrow transplantation model. Blood. 1997; 90:986-993. [PubMed: 9242527]

19. Saederup N, et al. Selective chemokine receptor usage by central nervous system myeloid cells in CCR2-red fluorescent protein knock-in mice. PLoS ONE. 2010; 5:e13693. [PubMed: 21060874]

20. Serbina NV, Pamer EG. Monocyte emigration from bone marrow during bacterial infection requires signals mediated by chemokine receptor CCR2. Nat. Immunol. 2006; 7:311-317. [PubMed: 16462739]

21. Ginhoux F, et al. The origin and development of nonlymphoid tissue CD103+ DCs. J. Exp. Med. 2009; 206:3115-3130. [PubMed: 20008528]

22. Davies LC, et al. A quantifiable proliferative burst of tissue macrophages restores homeostatic macrophage populations after acute inflammation. Eur. J. Immunol. 2011; 41:2155-2164. [PubMed: 21710478]

23. Ajami B, Bennett JL, Krieger C, McNagny KM, Rossi FM. Infiltrating monocytes trigger EAE progression, but do not contribute to the resident microglia pool. Nat. Neurosci. 2011; 14:11421149. [PubMed: 21804537]

24. Liu K, et al. Origin of dendritic cells in peripheral lymphoid organs of mice. Nat. Immunol. 2007; 8:578-583. [PubMed: 17450143]

25. Hill DA, et al. Metagenomic analyses reveal antibiotic-induced temporal and spatial changes in intestinal microbiota with associated alterations in immune cell homeostasis. Mucosal Immunol. 2010; 3:148-158. [PubMed: 19940845]

26. Epelman S, et al. Embryonic and adult-derived resident cardiac macrophages are maintained through distinct mechanisms at steady state and during inflammation. Immunity. 2014; 40:91-104. [PubMed: 24439267]

27. Bogunovic M, et al. Origin of the lamina propria dendritic cell network. Immunity. 2009; 31:513525. [PubMed: 19733489]

28. Tamoutounour $\mathrm{S}$, et al. Origins and functional specialization of macrophages and of conventional and monocyte-derived dendritic cells in mouse skin. Immunity. 2013; 39:925-938. [PubMed: 24184057]

29. Jakubzick C, et al. Minimal differentiation of classical monocytes as they survey steady-state tissues and transport antigen to lymph nodes. Immunity. 2013; 39:599-610. [PubMed: 24012416]

30. Chorro L, et al. Langerhans cell (LC) proliferation mediates neonatal development, homeostasis, and inflammation-associated expansion of the epidermal LC network. J. Exp. Med. 2009; 206:3089-3100. [PubMed: 19995948]

31. Mildner A, et al. Microglia in the adult brain arise from Ly-6ChiCCR2+ monocytes only under defined host conditions. Nat. Neurosci. 2007; 10:1544-1553. [PubMed: 18026096]

32. Epelman S, Lavine KJ, Randolph GJ. Origin and Functions of Tissue Macrophages. Immunity. 2014; 41:21-35. [PubMed: 25035951]

33. Smythies LE, et al. Mucosal IL-8 and TGF-beta recruit blood monocytes: evidence for cross-talk between the lamina propria stroma and myeloid cells. J. Leukoc. Bio. 2006; 80:492-499.

[PubMed: 16793909]

34. Ghigo C, et al. Multicolor fate mapping of Langerhans cell homeostasis. J. Exp. Med. 2013; 210:1657-1664. [PubMed: 23940255]

35. Ueda Y, et al. Commensal microbiota induce LPS hyporesponsiveness in colonic macrophages via the production of IL-10. Int Immunol. 2010; 22:953-962. [PubMed: 21051439]

36. Niess JH, Adler G. Enteric flora expands gut lamina propria CX3CR1+ dendritic cells supporting inflammatory immune responses under normal and inflammatory conditions. J. Immunol. 2010; 184:2026-2037.

37. Tamoutounour S, et al. CD64 distinguishes macrophages from dendritic cells in the gut and reveals the Th1-inducing role of mesenteric lymph node macrophages during colitis. Eur. J. Immunol. 2012; 42:3150-3166. [PubMed: 22936024] 
38. Muller AJ, et al. Salmonella gut invasion involves TTSS-2-dependent epithelial traversal, basolateral exit, and uptake by epithelium-sampling lamina propria phagocytes. Cell Host Microbe. 2012; 11:19-32. [PubMed: 22264510]

39. Nagashima R, Maeda K, Imai Y, Takahashi T. Lamina propria macrophages in the human gastrointestinal mucosa: their distribution, immunohistological phenotype, and function. J. Histochem. Cytochem. 1996; 44:721-731. [PubMed: 8675993]

40. Jung S, et al. Analysis of fractalkine receptor CX(3)CR1 function by targeted deletion and green fluorescent protein reporter gene insertion. Mol Cell Biol. 2000; 20:4106-4114. [PubMed: 10805752]

41. Boring L, et al. Impaired monocyte migration and reduced type 1 (Th1) cytokine responses in C-C chemokine receptor 2 knockout mice. J. Clin. Invest. 1997; 100:2552-2561. [PubMed: 9366570]

42. Bertrand JY, et al. Haematopoietic stem cells derive directly from aortic endothelium during development. Nature. 2010; 464:108-111. [PubMed: 20154733]

43. Bain CC, Mowat AM. CD200 receptor and macrophage function in the intestine. Immunobiology. 2012; 217:643-651. [PubMed: 22204814] 
a

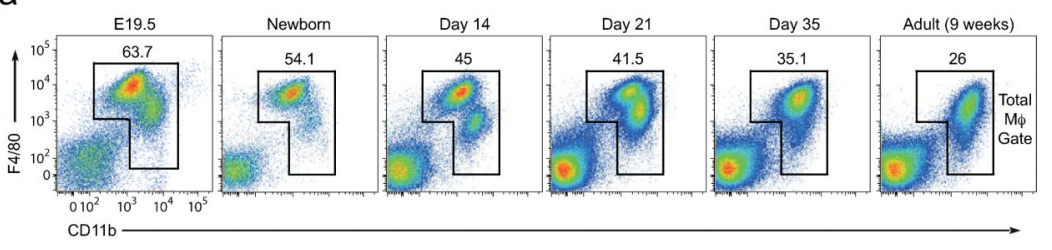

C

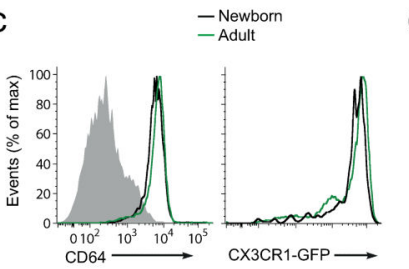

d

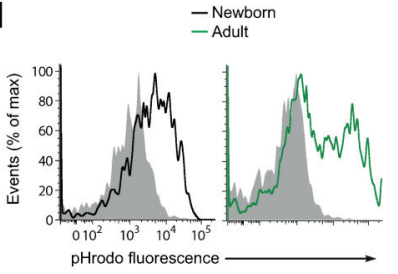

e

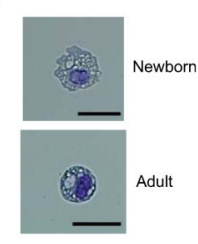

b

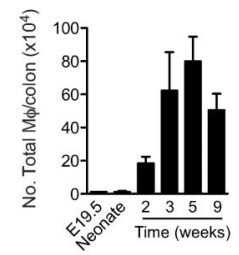

f

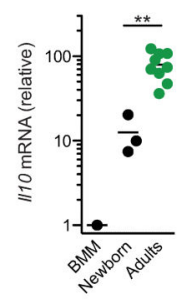

h

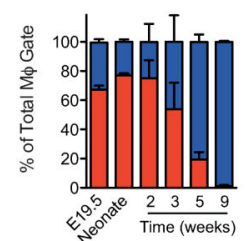

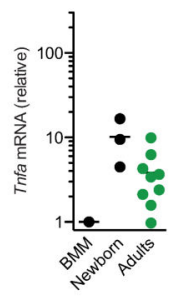

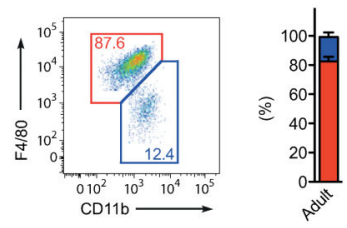

Figure 1. F4/80 and CD11b expression identifies macrophage subsets in neonatal and adult colon (a) F4/80 and CD11b expression by live CD45 ${ }^{+}$SiglecF ${ }^{-} \mathrm{Ly}_{6 \mathrm{G}^{-}} \mathrm{CD} 11 \mathrm{c}^{\mathrm{lo}}$ colonic $\mathrm{LP}$ cells from neonatal (day 2), day 14, day 21 , day 35 and 9 week old CX3CR $1^{+/ \text {gfp }}$ mice. (b) Absolute numbers of total $\mathrm{F} 4 / 80^{+} \mathrm{CD} 11 \mathrm{~b}^{+}$cells per colon in day 2, day 14 , day 21 , day 35 and 9 week old CX3CR1 $1^{+/ g f p}$ mice. (c) CD64 and CX3CR1-GFP expression by F4/80 $\mathrm{CD}_{11} \mathrm{~b}^{+}$colonic LP cells from newborn (day 2; black line) and 8 week old (green line) CX3CR1 $1^{+/ g f p}$ mice. Shaded histogram represents isotype control. (d) Phagocytic activity of $\mathrm{F} 4 / 80^{+} \mathrm{CD} 11 \mathrm{~b}^{+}$colonic LP cells from newborn (day 2 ) or adult $\mathrm{CX} 3 \mathrm{CR} 1^{+/ \mathrm{gfp}}$ mice measured by the uptake of pHrodo Escherichia coli bioparticles for $30-60$ mins at $37^{\circ} \mathrm{C}$ or $4^{\circ} \mathrm{C}$ as a control (shaded histograms). (e) Morphological appearance of F4/80 ${ }^{+} \mathrm{CD} 11 \mathrm{~b}^{+}$ colonic $\mathrm{m} \phi$ from newborn and adult mice. Scale bar $25 \mu \mathrm{m}$. (f) qRT-PCR of mRNA for IL10 and TNFa by F4/80 hi LP m $\phi$ from newborn (day 1) or adult mice, and BM-derived m $\phi$ (BMM). Results are mean expression relative to cyclophilin A (CPA) + 1SD obtained using the $2^{-\mathrm{d} \Delta \mathrm{C}(\mathrm{t})}$, with BMM set to $1 .{ }^{*} * P<0.01$ (Student's $t$-test). (g, h) Representative plots and mean frequencies of F4/80 ${ }^{\text {hi }} \mathrm{CD} 11 \mathrm{~b}^{\text {lo }}$ (red) and F4/80 ${ }^{\text {lo }} \mathrm{CD} 11 \mathrm{~b}^{+}$(blue) subsets of total colonic LP m $\phi$ from newborn (day 2), day 14, day 21, day 35 and 9 week old CX3CR $1^{+/ g f p}$ mice (g) or from 8 week old wild-type liver (h). Data are from one of $3(\mathbf{a}, \mathbf{b}, \mathbf{g}, \mathbf{h})$, or 2 independent experiments with two mice (c), of two independent experiments with 3 mice per group (d), or are representative images from two independent experiments (e). Results in $\mathbf{b}, \mathbf{g}, \mathbf{h}$ are means \pm 1 SD of 6 (neonate timepoint) or 4 (day 14, 21 and 35, and 9 week old timepoints) mice per group. Data from E19.5 embryos are from two experiments each using cells pooled from 8 mice. For qRT-PCR analysis (f), data represent 3 (neonate) or 9 (adult) biological replicates using RNA pooled from 1-2 adults or 5 neonates. 
a
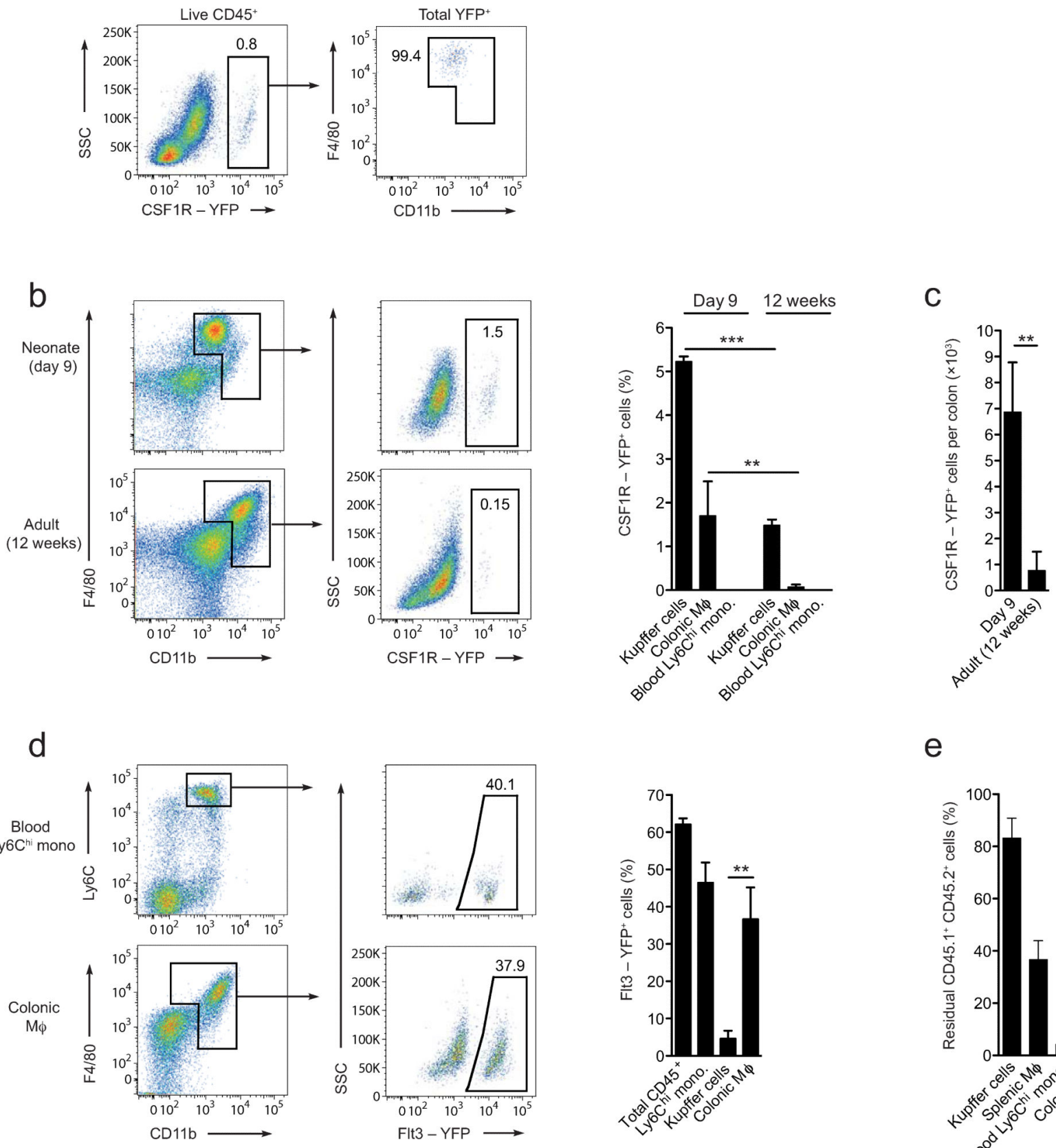

e

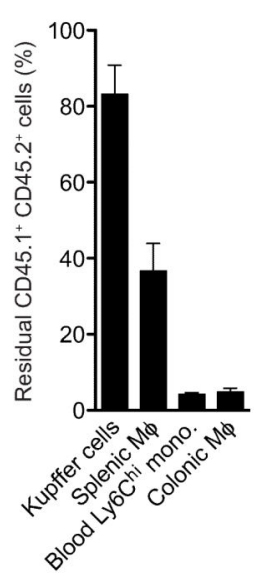

Figure 2. The colonic macrophage compartment is dependent on conventional hematopoiesis (a) YFP expression by total live CD45 ${ }^{+}$colonic leukocytes (left panel) from 9 day old progeny of Csf1r-mer-iCre-mer Rosa26-LSL-YFP mice injected with tamoxifen at E8.5 to pulse label CSF1R ${ }^{+}$YS macrophages (left panel); expression of F4/80 and CD11b by total $\mathrm{YFP}^{+}$cells (right panel). (b) Representative YFP expression by F4/80 ${ }^{+} \mathrm{CD} 11 \mathrm{~b}^{+}$colonic LP cells from 9 day or 12 week old progeny of Csfl $r$-mer-iCre-mer Rosa26-LSL-YFP mice treated as in $\mathbf{a}$. Bar chart shows the mean frequency of $\mathrm{YFP}^{+}$cells amongst $\mathrm{F} 4 / 80^{\text {hi }} \mathrm{CD} 11 \mathrm{~b}^{\text {lo }}$ liver Kupffer cells, total F4/80 ${ }^{+} \mathrm{CD} 11 \mathrm{~b}^{+}$colonic LP cells and amongst Ly6Chi blood 
monocytes from 9 day or 12 week old progeny of Csflr-mer-iCre-mer Rosa26-LSL-YFP mice treated as above. $* * P<0.01, * * * P<0.0001$ (Student's $t$-test). (c) Absolute number of eYFP-expressing F4/80 ${ }^{+} \mathrm{CD} 11 \mathrm{~b}^{+}$colonic LP cells from 9 day or 12 week old adult progeny of Csf $1 r$-mer-iCre-mer Rosa26-LSL-YFP mice. (d) Representative eYFP expression (upper panels) and mean eYFP expression (lower panel) by total $\mathrm{CD}^{4} 5^{+}$blood leukocytes, $\mathrm{Ly} 6 \mathrm{C}^{\text {hi }}$ blood monocytes, $\mathrm{F} 4 / 80^{\text {hi }} \mathrm{CD} 11 \mathrm{~b}^{\text {lo }}$ liver $\mathrm{KC}$ and colonic F4/80 ${ }^{+} \mathrm{CD} 11 \mathrm{~b}^{+}$cells from 8 week old progeny of Flt3-Cre Rosa26-LSL-YFP mice. ${ }^{*} * P<0.005$ (Student's $t$-test). (e)

Proportions of $\mathrm{CD} 45.1^{+} \mathrm{CD} 45.2^{+}$residual host cells amongst Ly6Chi blood monocytes, total $\mathrm{F} 4 / 80^{+} \mathrm{CD} 11 \mathrm{~b}^{+}$colonic LP cells, F4/80 ${ }^{\text {hi }} \mathrm{CD} 11 \mathrm{~b}^{\text {lo }}$ liver Kupffer cells and F4/80 $0^{\text {hi }} \mathrm{CD} 11 \mathrm{~b}^{\text {lo }}$ splenic macrophages of WT:Ccr2 ${ }^{-/-}$mixed BM chimeric mice 8 weeks after reconstitution. a, b, c: Data are means +1 SD and are pooled from two independent experiments with 3 or 4 mice per group (12 week old), or from one experiment with 3 mice (9 day old). d, e: Data are means +1 SD and are from one of two independent experiments with 3 mice. 
a

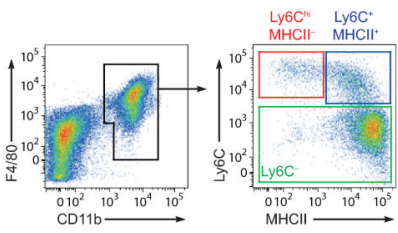

b

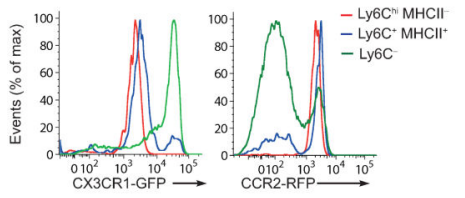

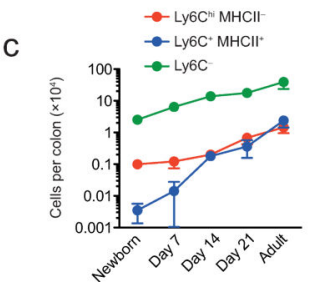

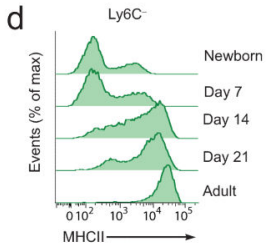

e

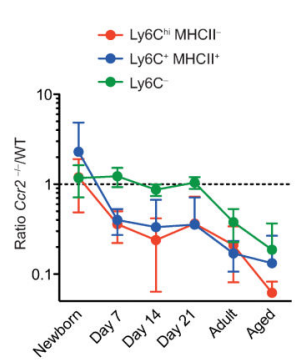

f

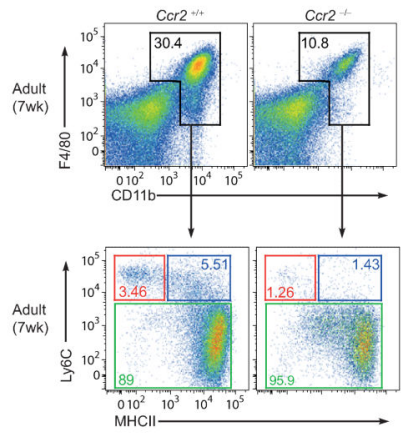

9
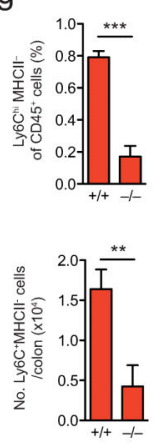
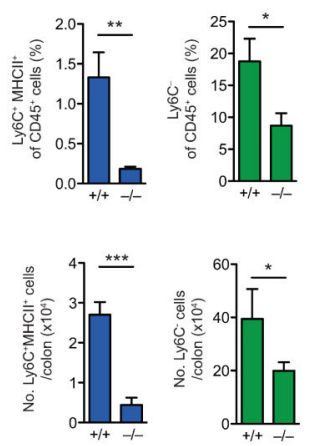

h
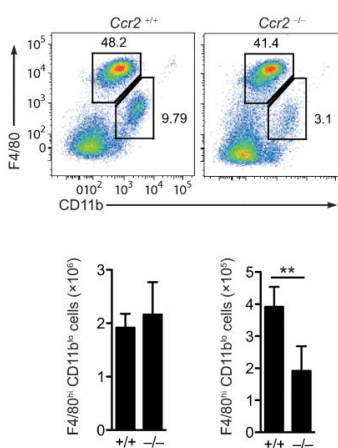

Figure 3. Maturation and CCR2-dependence of intestinal macrophage development (a) Ly6C and MHCII expression by colonic F4/80 ${ }^{+} \mathrm{CD} 11 \mathrm{~b}^{+}$cells from adult CX3CR $1^{+/ \mathrm{gfp}}$

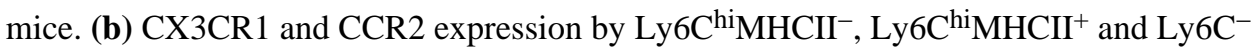
subsets from $\mathrm{CX} 3 \mathrm{CR} 1^{+/ \mathrm{gfp}}$ and CCR2 $2^{+/ \mathrm{rfp}}$ mice respectively. (c) Absolute numbers of colonic $\mathrm{Ly}_{6 \mathrm{C}}{ }^{\mathrm{hi}} \mathrm{MHCII}^{-}, \mathrm{Ly}^{+} \mathrm{C}^{+} \mathrm{MHCII}{ }^{+}$and $\mathrm{Ly}^{-} \mathrm{C}^{-}$subsets from newborn (day 0-1), day 7 , day 14, day 21 and 7-8 week old CX3CR1 $1^{+/ g f p}$ mice. (d) MHCII expression by

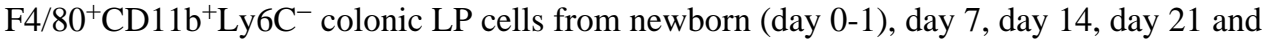
7-8 week old CX3CR1 ${ }^{+/ g f p}$ mice. (e) Numbers of $\mathrm{Ly}_{6 \mathrm{Ch}} \mathrm{MHCII}^{-}, \mathrm{Ly}_{6 \mathrm{C}}^{+} \mathrm{MHCII}^{+}$and Ly6C ${ }^{-}$subsets in colon of newborn (day 0-1), day 7, day 14, day 21, 7 week old and in 9-12 month old adult $C c r 2^{-/-}$mice, shown as ratios to the equivalent populations in age-matched Ccr $2^{+/+}$mice. (f) Representative F4/80 and CD11b expression by live $\mathrm{CD}^{+} 5^{+}$SiglecF ${ }^{-} \mathrm{Ly}_{6 \mathrm{G}^{-}} \mathrm{CD} 11 \mathrm{c}^{\text {lo }}$ colonic LP cells and Ly6C and MHCII expression by total $\mathrm{F} 4 / 80^{+} \mathrm{CD} 11 \mathrm{~b}^{+}$cells from 7 week old $\mathrm{Ccr} 2^{+/+}$or $\mathrm{Ccr} 2^{-/-}$mice. (g) Mean proportions and absolute numbers of $\mathrm{Ly} 6 \mathrm{C}^{\text {hi }} \mathrm{MHCII}^{-}, \mathrm{Ly} 6 \mathrm{C}^{+} \mathrm{MHCII}^{+}$and $\mathrm{Ly}^{-} \mathrm{C}^{-}$subsets in colon of 7 week old $C c r 2^{+/+}$or $C c r 2^{-/-}$mice. $* P<0.05$, $* * P<0.01$, ***P<0.001 (Student's $t$-test). (h) Representative F4/80 and CD11b expression by live CD45 ${ }^{+}$SiglecF $^{-} \mathrm{Ly}_{6 \mathrm{G}^{-}} \mathrm{CD}_{11} \mathrm{c}^{\text {lo }}$ liver cells from 8 week old $C c r 2^{+/+}$or $C c r 2^{-/-}$mice. Bar charts show the absolute numbers of $\mathrm{F} 4 / 80^{\text {hi }} \mathrm{CD} 11 \mathrm{~b}^{\text {lo }}$ and $\mathrm{F} 4 / 80^{\text {lo }} \mathrm{CD} 11 \mathrm{~b}^{+}$cells from livers of $8 \mathrm{wk}$ old $\mathrm{Ccr} 2^{+/+}$or $\mathrm{Ccr} 2^{-/-}$mice. $* * P<0.01$ (Student's $t$-test). Data are representative of 3 independent experiments $(\mathbf{a}, \mathbf{f}, \mathbf{g}, \mathbf{h}$ and $\mathrm{Cx} 3 \mathrm{crl}^{+/ \mathrm{gfp}}$ mice in $\left.\mathbf{b}\right)$, or from one experiment $\left(C \mathrm{cr} 2^{+/ \mathrm{rfp}}\right.$ mice in $\left.\mathbf{b}\right)$, or are pooled from two independent time course experiments $(\mathbf{c}, \mathbf{d}, \mathbf{e})$. Aged mice were examined in one experiment. Results in $\mathbf{c}, \mathbf{e}, \mathbf{g}, \mathbf{h}$ are means \pm 1 SD of 6-8 (c, e) or 3-4 mice (g, h) per group. 

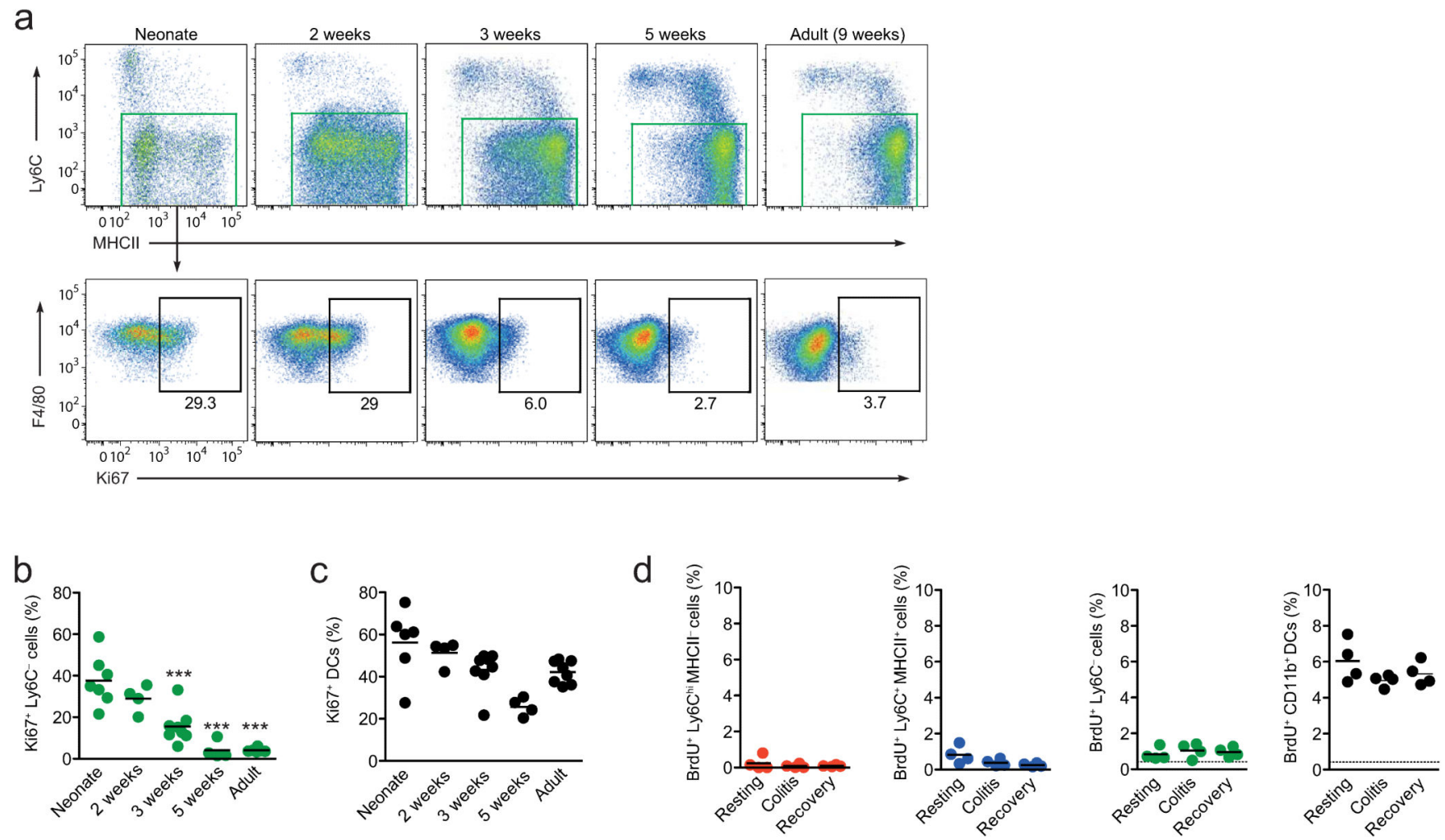

Figure 4. Proliferative activity of intestinal macrophages in situ

(a) Expression of $\mathrm{Ki} 67$ by $\mathrm{F} 4 / 80^{+} \mathrm{CD} 11 \mathrm{~b}^{+} \mathrm{Ly} 6 \mathrm{C}^{-}$colonic $\mathrm{m} \phi$ from early neonate (day 3), day 14 , day 21 , day 35 and 9-12 week old adult CX3CR $1^{+/ g f p}$ mice. (b, c) Proportions of

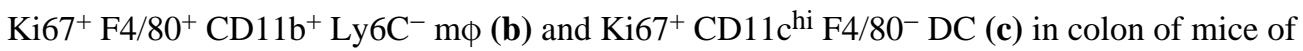
different ages. The results are of 4-7 individual mice pooled from 2 independent experiments. Each dot represents an individual mouse. ${ }^{*} * P<0.0001$ (One way ANOVA followed by Bonferroni's multiple comparison test). (d) Proportion of $\mathrm{BrdU}^{+}$cells amongst $\mathrm{CD}^{+} 4^{+} \mathrm{Ly}_{6 \mathrm{C}^{\mathrm{hi}} \mathrm{MHCII}}{ }^{-}, \mathrm{Ly}^{+} \mathrm{CHHCII}^{+}, \mathrm{Ly}^{+} \mathrm{C}^{-}$cells and CD64- $\mathrm{CD}^{-} 1 \mathrm{~b}^{+}$DC from the colons of resting mice, mice administered 2\% DSS for 3 days (colitis) and mice given DSS for 3 days followed by 3 days of normal water (recovery). Mice were administered BrdU 3 hours prior to sacrifice and the dotted line represents the limit of detection as shown by BrdU staining in a non-DNase treated control sample. Data are pooled from two independent experiments with 4-7 seven mice at each time point $(\mathbf{a}, \mathbf{b}, \mathbf{c})$, or are from one of two independent experiments with 4 mice per group $(\mathbf{d})$. Each circle represents an individual mouse. 
a

Colonic LP
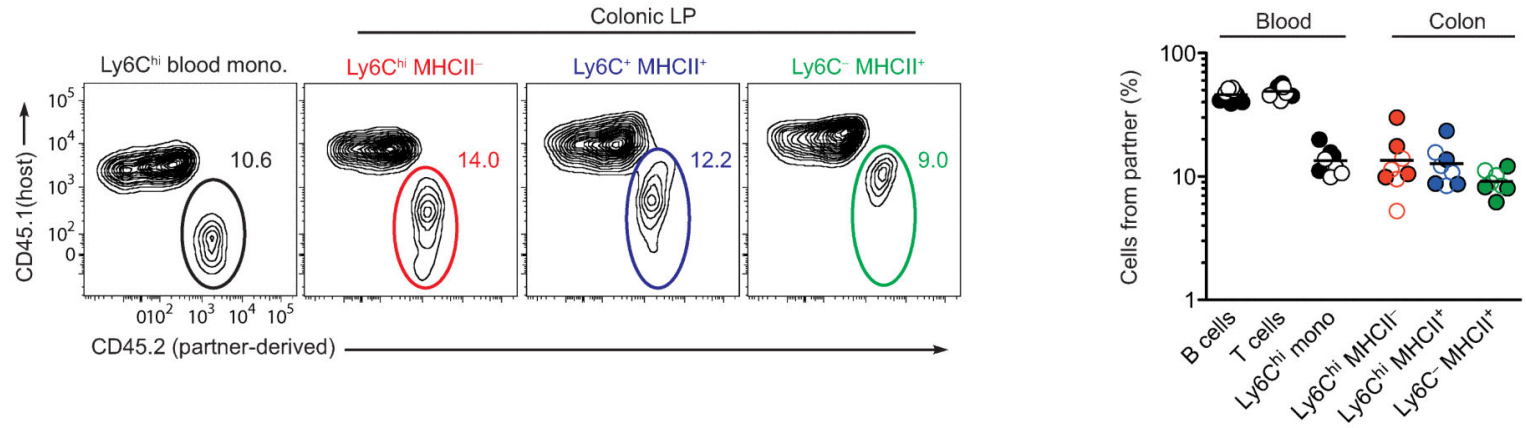

b

Colonic LP
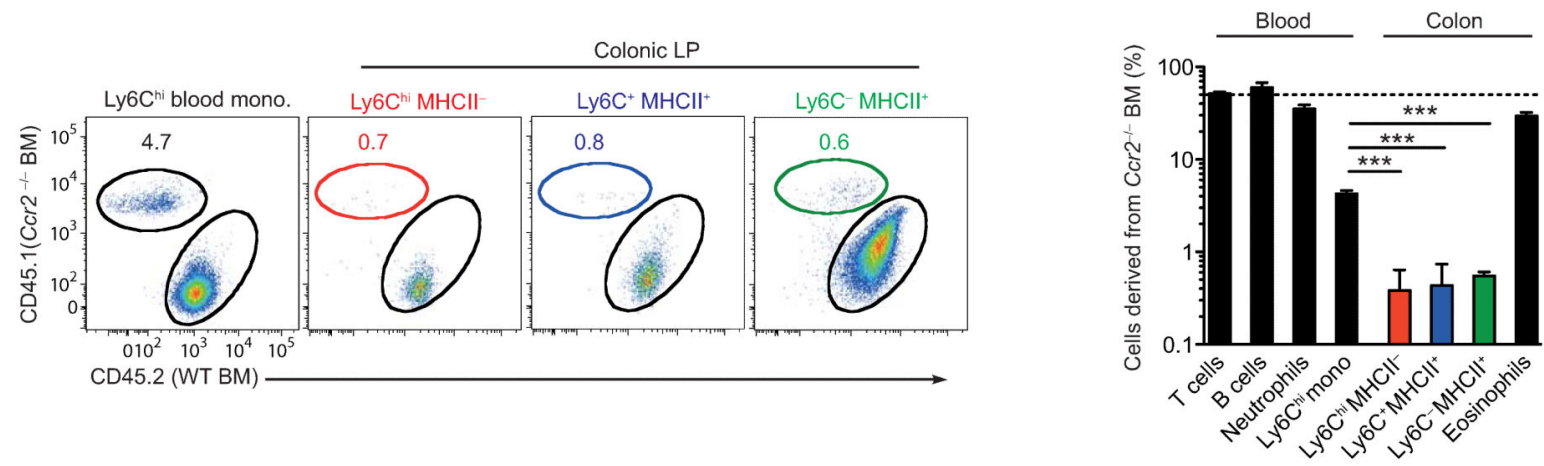

C
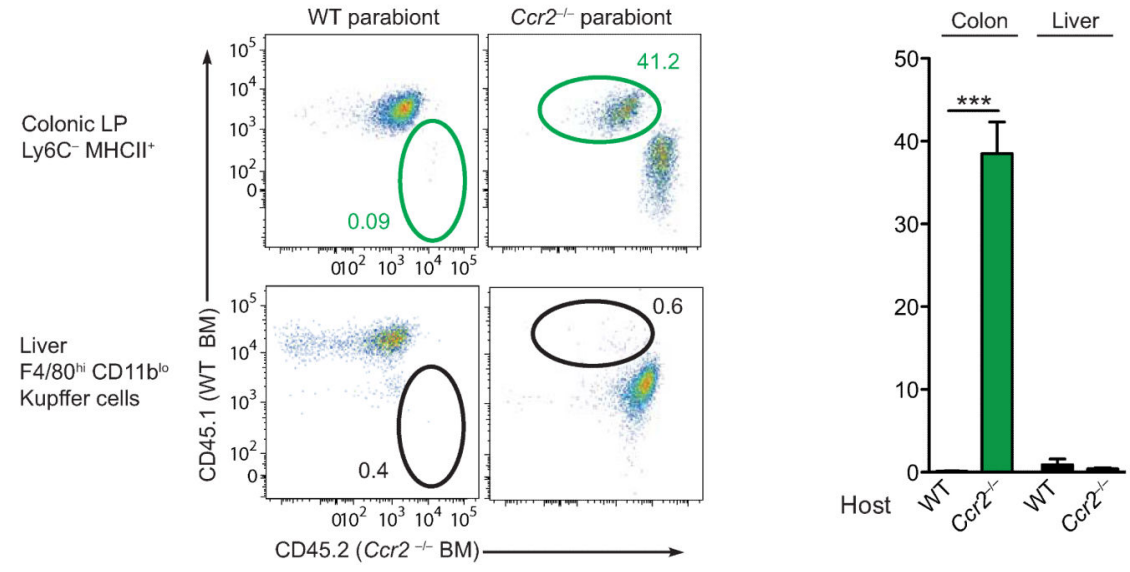

Figure 5. Colonic macrophages derive from classical $\mathrm{Ly}_{6} \mathrm{C}^{\mathrm{hi}}$ monocytes

(a) Representative chimerism of $\mathrm{Ly} 6 \mathrm{C}^{\text {hi }}$ blood monocytes and $\mathrm{Ly} 6 \mathrm{C}^{\mathrm{hi}} \mathrm{MHCII}^{-}$,

$\mathrm{Ly}_{6 \mathrm{C}^{+}} \mathrm{MHCII}^{+}$and $\mathrm{Ly} 6 \mathrm{C}^{-}$subsets of colonic $\mathrm{F} 4 / 80^{+} \mathrm{CD} 11 \mathrm{~b}^{+}$cells from the CD $45.1^{+}$ partner of wild-type:wild-type parabionts 10 weeks after joining. Scatter plot shows the proportions of non-host derived cells amongst $\mathrm{B}$ and $\mathrm{T}$ lymphocytes and Ly $6 \mathrm{C}^{\mathrm{hi}}$ monocytes in blood, and colonic $\mathrm{Ly}_{6} \mathrm{Ch}^{\mathrm{Mi}} \mathrm{MHCII}^{-}$, $\mathrm{Ly}_{6 \mathrm{C}^{+}} \mathrm{MHCII}^{+}$and $\mathrm{Ly} 6 \mathrm{C}^{-}$subsets from individual CD $45.1^{+}$(open circles) and CD45.2 (filled circles) parabionts. (b) Representative dot plots of the chimerism of Ly6 $\mathrm{C}^{\text {hi }}$ blood monocytes and of the colonic $\mathrm{Ly}_{6 \mathrm{C}}{ }^{\mathrm{hi}} \mathrm{MHCII}{ }^{-}$, 
$\mathrm{Ly}_{6 \mathrm{C}^{+}} \mathrm{MHCII}^{+}$and $\mathrm{Ly}_{6 \mathrm{C}}{ }^{-}$subsets from wild-type $\left(\mathrm{CD} 45.2^{+}\right): \mathrm{Ccr}^{-{ }^{--}}\left(\mathrm{CD} 45.1^{+}\right)$mixed BM chimeric mice. Bar chart shows the mean proportions of cells derived from $\mathrm{Ccr}^{-/-}$ $\mathrm{CD} 45.1^{+} \mathrm{BM}$ amongst $\mathrm{CD}^{+} \mathrm{T}$ cells, $\mathrm{CD} 19^{+} \mathrm{B}$ cells, Ly6 $\mathrm{C}^{\text {hi }}$ monocytes and $\mathrm{Ly}_{6 \mathrm{G}}{ }^{+}$ neutrophils in blood, and amongst the colonic $\mathrm{Ly}_{6 \mathrm{Ch}} \mathrm{MHCII}^{-}, \mathrm{Ly} \mathrm{C}^{+} \mathrm{MHCII}^{+}$and $\mathrm{Ly}^{-} \mathrm{C}^{-}$ subsets, together with $\mathrm{F} 4 / 80^{+} \mathrm{CD} 11 \mathrm{~b}^{+} \mathrm{MHCII}^{-} \mathrm{SSC}^{\mathrm{hi}}$ eosinophils in the colon of WT $\left(\mathrm{CD} 45.1^{+}\right): \mathrm{Ccr}^{-/-}\left(\mathrm{CD} 45.2^{+}\right)$mixed BM chimeric mice. $* * * P<0.0001$ (Student's $t$-test). (c) Representative non-host chimerism amongst Ly $6 \mathrm{C}^{-}$colonic $\mathrm{m} \phi$ and $\mathrm{F} 4 / 80^{\text {hi }} \mathrm{CD} 11 \mathrm{~b}^{\text {lo }}$ liver Kupffer cells from the WT partner (left plots) and the $C \mathrm{cr} 2^{-/-}$partner (right plots) of WT$\mathrm{Ccr}^{-/-}$parabiotic mice 10 weeks after establishment of parabiosis. Bar chart shows the mean proportion of non-host chimerism amongst Ly6C ${ }^{-}$colonic $\mathrm{m} \phi$ and $\mathrm{F} 4 / 80^{\mathrm{hi}} \mathrm{CD} 11 \mathrm{~b}^{\text {lo }}$ liver Kupffer cells in the WT and $C c r 2^{-/-}$partner of WT-C $c r 2^{-/-}$parabiotic mice. $* * * P<0.0001$ (Student's $t$-test). Data are from one experiment (a), or from one of two independent experiments $(\mathbf{b})$, or are pooled from three experiments $(\mathbf{c})$. Results are the means \pm 1 SD of 3 (b) or 4-6 mice per group (c). 
a

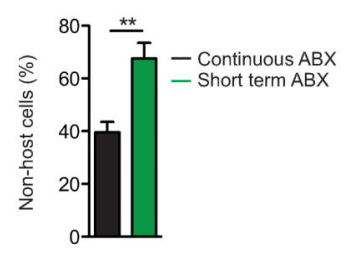

C

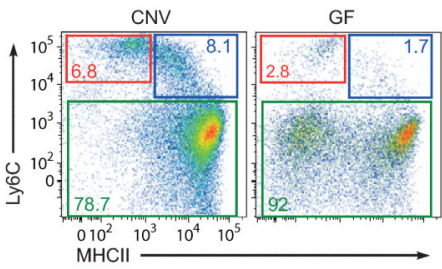

b
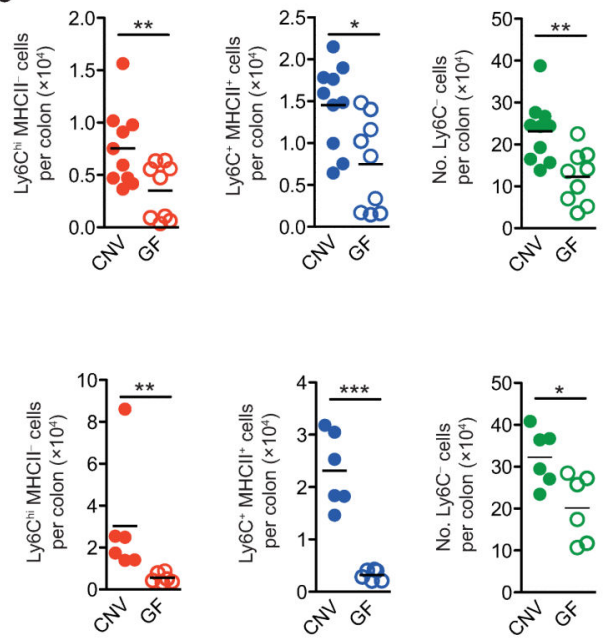
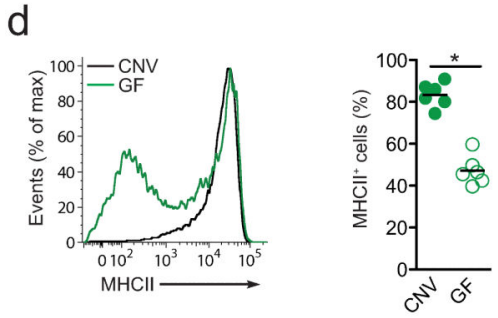

Figure 6. Influence of the commensal microbiota on the development of colonic macrophages (a) Non-host chimerism of $\mathrm{CD} 64^{+} / \mathrm{F} 4 / 80^{+} \mathrm{Ly}_{6 \mathrm{C}}-$ colonic $\mathrm{m} \phi$ in $C \mathrm{cr} 2^{-/-}$partners of WT$\mathrm{Ccr} 2^{-/-}$parabiotic mice given broad spectrum antibiotics for the first 4 weeks after surgery (Abx. 4wks), compared with the group of mice shown in Fig. 5c that received antibiotics for the entire 8 weeks of the study (continuous Abx). **P<0.01 (Student's $t$-test). (b) Absolute

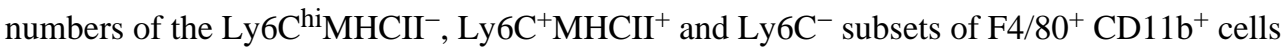
per colon of adult conventionally housed (CNV) and germ free (GF) mice. $* P<0.05$, ** $P<0.005$ (Mann Whitney). (c) Representative dot plots of Ly6C and MHCII expression by $\mathrm{F} 4 / 80^{+} \mathrm{CD} 11 \mathrm{~b}^{+}$colonic LP cells from 3 week old $\mathrm{Rag}^{-/-} \mathrm{CNV}$ and GF mice. Scatter plots show the absolute numbers of the $\mathrm{Ly}_{6 \mathrm{C}}{ }^{\mathrm{hi}} \mathrm{MHCII}^{-}, \mathrm{Ly} \mathrm{C}^{+} \mathrm{MHCII}^{+}$and $\mathrm{Ly} \mathrm{C}^{-}$subsets of $\mathrm{F} 4 / 80^{+} \mathrm{CD} 11 \mathrm{~b}^{+}$cells per colon of individual 3 week old $\mathrm{CNV}$ and GF mice. ${ }^{*} P<0.05$, $* * * P<0.0001$ (Mann Whitney). (d) Representative expression of MHCII by F4/80 $0^{+} \mathrm{CD}_{11 \mathrm{~b}^{+}}$ Ly6 $\mathrm{C}^{-}$colonic LP cells from 3 week old mice and mean proportion of $\mathrm{F} 4 / 80^{+} \mathrm{CD} 11 \mathrm{~b}^{+}$ Ly6C $^{-} \mathrm{MHCII}^{+}$cells amongst total $\mathrm{F} 4 / 80^{+} \mathrm{CD} 11 \mathrm{~b}^{+}$colonic LP cells. $* P<0.05$ (Student's $t$ test). Data are means $+1 \mathrm{SD}$ of results pooled from two independent experiments using 3 (a) or 10 mice per group (b), or are from one of two independent experiments with 6 mice per group $(\mathbf{c}, \mathbf{d})$. 